\title{
Identification and characterization of the major pseudocoelomic proteins of the giant kidney worm, Dioctophyme renale
}

\author{
A. Nahili Giorello ${ }^{1}$, Malcolm W. Kennedy ${ }^{2,3}$, Marcos J. Butti ${ }^{4}$, Nilda E. Radman ${ }^{4}$, Betina Córsico ${ }^{1}$ \\ and Gisela R. Franchini ${ }^{1^{*}}$
}

\begin{abstract}
Background: The giant kidney worm, Dioctophyme renale, is a debilitating and potentially lethal parasite that inhabits and destroys, typically host's right kidney, and may also be found in ectopic sites. It is circumglobally distributed, mainly in dogs, and is increasingly regarded as a threat to other domestic animals and humans. There is little information on the parasite's true incidence, or immune responses to it, and none on its biochemistry and molecular biology.

Results: We characterised the soluble proteins of body wall, intestine, gonads and pseudocelomic fluid (PCF) of adult parasites. Two proteins, P17 and P44, dominate the PCF of both male and females. P17 is of 16,622 Da by mass spectrometry, and accounts for the intense red colour of the adult parasites. It may function to carry or scavenge oxygen and be related to the 'nemoglobins' found in other nematode clades. P44 is of 44,460 Da and was found to associate with fatty acids by thin layer chromatography. Using environment-sensitive fluorescent lipid probes, P44 proved to be a hydrophobic ligand-binding protein with a binding site that is highly apolar, and competitive displacement experiments showed that P44 binds fatty acids. It may therefore have a role in distributing lipids within the parasites and, if also secreted, might influence local inflammatory and tissue responses. $\mathrm{N}$-terminal and internal peptide amino-acid sequences of P44 indicate a relationship with a cysteine- and histidinerich protein of unknown function from Trichinella spiralis.
\end{abstract}

Conclusions: The dominant proteins of D. renale PCF are, like those of large ascaridids, likely to be involved in lipid and oxygen handling, although there is evidence of strong divergence between the two groups.

Keywords: Dioctophyme renale, Lipid-binding proteins, Nematodes, Emerging zoonoses

\section{Background}

Dioctophyme renale, the giant kidney worm, is the largest known parasitic nematode of land vertebrates. It develops in, and completely destroys, mammalian kidneys it occupies, and is thereby a debilitating and potentially lethal parasite of dogs, domestic and wild animals, and humans. It is highly pathogenic and particularly common in dogs in South America [1-4], where it also severely affects wild animals such as bush dog (Speothos venaticus) [5], southern two-toed sloth (Choloepus

\footnotetext{
* Correspondence: gfranchini@conicet.gov.ar

${ }^{1}$ Instituto de Investigaciones Bioquímicas de La Plata (INIBIOLP), Facultad de Ciencias Médicas, Universidad Nacional de La Plata, La Plata, Argentina

Full list of author information is available at the end of the article
}

didactylus) [6], crab-eating fox (Cerdocyon thous) [7] and maned wolf (Chrysocyon brachyurus) [8-10]. The latter is the largest native canid in South America and is considered as near threatened by IUCN (International Union for the Conservation of Nature - Red List 3.1), and dioctophymatosis is now included among threats to its wild population [11, 12]. Climatic change, environmental degradation, deforestation, and compromised sanitation around human settlements, have resulted in many biodiversity hotspots undergoing severe habitat fragmentation that has forced wild animals to migrate and face new threats, among which are increased vulnerabilities to $D$. renale. During such displacements, wild and feral species overlap in distribution with domestic 
animals, and potentially expose domestic animals and humans to sources of dioctophymatosis [13]. There are, for instance, sporadic reports of the infection in cattle, horses, pigs and rats [5, 14-16]. Dioctophyme renale is regarded as a causative agent of zoonotic disease in humans, in which the true incidence of exposure is unknown, though it has been an unequivocal direct cause of fatalities, or associated with renal carcinoma [17-20].

Adults of $D$. renale locate in the renal pelvis of one kidney (usually only the right one) of their definitive hosts, destroying the renal parenchyma and leaving a thin capsule enclosing a nest of mating parasites. The unaffected kidney usually hypertrophies to compensate for the complete loss of its counterpart's function [8] such that there may be no overt clinical signs of infection for some time. Eggs are dispersed via urine into the environment, where they are thought to be ingested by an annelid (usually an oligochaete) in which the parasite's larvae develop to the L3 stage [21]. If infected annelids are not consumed directly by a definitive host, the larvae can persist in paratenic hosts such as frogs, fishes, and rodents, and even a fresh water turtle [22].

Dioctophyme renale is globally distributed but is more common in South America than elsewhere. Dogs living close to rivers are commonly infected, as diagnosed by urine analysis, ultrasonography, surgery, or at necropsy $[3,4]$. Although the parasite is usually located in one of the kidneys, infection can be bilateral, and worms may also develop to adulthood ectopically in sites such as the abdominal cavity, uterus, ovary, mammary gland, urethra, subcutaneous tissues of the inguinal region, and mesenteric lymph nodes $[1,23]$. Recent studies have implemented a more sensitive technique for detecting and counting Dioctophyme renale eggs in urine [24]. Nevertheless, this and other currently used diagnostic methods for dioctophymatosis may fail to detect premature, infertile, single sex, or ectopic infections, and the equipment required makes screening for the infection in rural and economically deprived areas difficult. Recently published data, however, indicate that soluble antigens from the digestive tract of $D$. renale may provide the basis of a serodiagnostic method for dioctophymatosis in dogs [25]. A serodiagnostic method applicable to humans is also urgently required given that people living in poverty, poor sanitary conditions, and of poor sociological backgrounds, may consume intermediate hosts and become infected as well as contributing to the persistence of the parasite by feeding their dogs with uncooked material from the same paratenic hosts.

Despite the importance and threat that dioctophymatosis poses to humans, domestic, and endangered wild animals, there is a paucity of molecular and immunological information on this parasite. We here begin to address this neglect with a report on a comparison of the protein profiles of its tissues, concentrating on the most readily available source of the parasite's soluble proteins, its pseudocelomic body fluid (PCF). We then concentrated on the two most abundant PCF proteins that occur in both males and females with a view to establishing their biological functions.

\section{Methods}

\section{Parasite material}

Nematodes were isolated by nephrectomy of affected dogs diagnosed in surrounding areas of La Plata, Argentina. Freshly-collected parasites were washed several times with phosphate buffered saline $\mathrm{pH}$ 7.4 (PBS) and placed in a Petri dish. A small incision was made close to the anterior end of adults worms using a scalpel and PCF was allowed to drain freely into the Petri dish, filtered $(0.22 \mu \mathrm{m}$ pore size $)$ and stored at $-20{ }^{\circ} \mathrm{C}$. The rest of the parasites' bodies were dissected into body wall (BW), intestine (I) and gonads (testis, T; ovary, O), which were homogenized using a mechanical tissue grinder. All samples were in PBS buffer containing a cocktail of protease inhibitors (Protease Inhibitor Cocktail Set III Calbiochem cat. 539,134, Merck Millipore, San Diego, USA) and stored at $-20{ }^{\circ} \mathrm{C}$. Protein content was estimated using the Bradford assay [26].

\section{Polyacrylamide gel electrophoresis (SDS-PAGE)}

Protein gels $(1 \mathrm{~mm}$ thick, $6 \%$ stacking, $15 \%$ acrylamide final separating) were run in a Miniprotean II (Bio-Rad, Hercules, USA) slab gel apparatus. Samples were heated in a heating block set for $100{ }^{\circ} \mathrm{C}$, with $5 \% \quad \beta$ mercaptoethanol added for reducing conditions. Following electrophoresis, gels were stained with Coomassie Brilliant Blue R (Sigma-Aldrich, B0770, Saint Louis, USA) overnight, and destained using a 30\% ethanol/10\% acetic acid/60\% water v/v/v solution. Apparent molecular masses were estimated by mobility relative to standard marker proteins (GE Healthcare UK Limited GE; LMW 17-0446-01, Amersham Place, Buckinghamshire, $\mathrm{UK})$, and are indicated in kilodaltons $(\mathrm{kDa})$.

\section{Size exclusion chromatography}

Size exclusion chromatography (SEC) was carried out using an Âkta FPLC System (GE Healthcare Life Sciences, Uppsala, Sweden) to purify the major proteins from PCF and to indicate their aggregation state. Briefly, $400 \mu \mathrm{l}$ of filtered PCF were loaded onto a Superdex 75 HR 10/30 column (GE Healthcare Life Sciences, Uppsala, Sweden) pre-equilibrated with PBS. A flow rate of $0.7 \mathrm{ml} / \mathrm{min}$ was used, and samples were collected using an inline F900 fraction collector. The column was precalibrated using bovine serum albumin $(66 \mathrm{kDa})$, carbonic anhydrase $(29 \mathrm{kDa})$ and cytochrome $c(12 \mathrm{kDa})$ as protein standards under the same chromatography 
conditions, and molecular size estimations of the proteins were undertaken as described [27]. Samples, as well as standard proteins, were analysed twice under the same conditions to ensure reproducibility. Elution profiles were recorded following the UV absorption at 215 and $280 \mathrm{~nm}$.

\section{Lipid-binding activity in native polyacrylamide gels}

In order to identify lipid-binding proteins present in PCF, samples were pre-incubated with the environmentsensitive fluorescent probe 11-[5-(dimethylamino)-1naphthalenesulfonylamino] undecanoic acid (DAUDA, Invitrogen Molecular Probes, Eugene, USA). One $\mu \mathrm{l}$ of a $60 \mu \mathrm{M}$ DAUDA solution was added to $20 \mu \mathrm{l}$ of PCF at a concentration of $6-10 \mu \mathrm{g} / \mu \mathrm{l}$ and incubated for $30 \mathrm{~min}$ at $20{ }^{\circ} \mathrm{C}$. As a positive control, a well-characterised fatty acid and retinol-binding protein of nematodes [28-30] (recombinant ABA-1A from Ascaris suum) was also included. Samples pre-incubated with DAUDA were then resolved in $15 \%$ gels without addition of SDS, reducing agent, or heating. Without any further staining, fluorescence emission was visualised using an Image Quant 350 (28-9272-95, GE Healthcare Life Sciences, Uppsala, Sweden), using the UV light as excitation light source and a fluorescein filter set $(537 / 35 \mathrm{~nm})$ for emission detection. After the fluorescence image was captured a final step of gel staining with Coomassie Brilliant Blue $\mathrm{R}$ was carried out on the same gel.

\section{Lipid extraction and analysis}

Total lipids were extracted from PCF or purified proteins as previously described [31,32], with minor modifications. PCF or protein fractions $(0.5 \mathrm{ml})$ were mixed with $5 \mathrm{ml} \mathrm{CHCl}_{3}: \mathrm{CH}_{3} \mathrm{OH}(2: 1 \mathrm{v} / \mathrm{v})$ and vigorously shaken for $15 \mathrm{~min}$ in an ice bath. The homogenate was stored overnight at $-20{ }^{\circ} \mathrm{C}$ and the next day $250 \mu \mathrm{l}$ of $2.9 \% \mathrm{w} / \mathrm{v} \mathrm{NaCl}$ solution was added and vortexed. The aqueous and solvent phases were allowed to separate at room temperature and by a centrifugation step. The upper, aqueous phase, was discarded and the lower phase containing lipids was recovered and dried under a stream of nitrogen gas, re-dissolved in $\mathrm{CHCl}_{3}$ and stored at $-20{ }^{\circ} \mathrm{C}$. Lipid classes found in PCF samples were resolved by thin layer chromatography (TLC) using previously described methods and solvent systems by [32] Lipid samples obtained from PCF along with lipid standards were spotted onto TLC plates $(20 \times 20 \mathrm{~cm}$; previously activated at $100{ }^{\circ} \mathrm{C}$ for $30 \mathrm{~min}$ ) and developed with methyl acetate/ isopropanol/ chloroform/ methanol/ $0.25 \% \mathrm{KCl}$ (25:25:25:10:9, by volume) for polar lipids. Rat liver lipids previously obtained in our lab were included as reference. Plates were developed using the sulfuric acid charring method. Briefly, plates were sprayed with a $8 \% \mathrm{CuSO}_{4}(\mathrm{w} / \mathrm{v}), 10 \% \mathrm{H}_{3} \mathrm{PO}_{4}(\mathrm{v} / \mathrm{v})$ solution and the lipids visualized as black carbon depots formed after heating the plates at $180{ }^{\circ} \mathrm{C}$ for $1 \mathrm{~h}$.

\section{Spectrofluorimetry}

Fluorescence experiments were performed with a Fluorolog-3 Spectrofluorometer (Horiba-Jobin Yvon, Edison, NJ). Buffer alone was used to correct for Raman scattering where stated. Two environment-sensitive fluorescence probes were used, the non-specific hydrophobic probe 8-anilinonaphthalene-1-sulfonic acid (ANS) and the fluorophore-tagged fatty acid 11-[5(dimethylamino)-1-naphthalene sulfonylamino] undecanoic acid (DAUDA; see above). The latter is considered to be more selective of dedicated lipid-binding sites in proteins and the fluorescence emission spectrum of its dansyl fluorophore is taken to indicate the degree of apolarity of its environment [33]. To detect lipid-binding activity among proteins of PCF, $5 \mu \mathrm{l}$ of a $60 \mu \mathrm{M}$ DAUDA stock solution in ethanol were added to $200 \mu \mathrm{l}$ of each fraction after size exclusion chromatography to monitor lipid-binding activity. Spectra were recorded using $\lambda_{\text {exc }}=345 \mathrm{~nm}, \lambda_{\mathrm{em}}=360-650 \mathrm{~nm}$. DAUDA stock solutions were prepared in ethanol and then diluted in PBS for use in the assays. After SEC purification P44 was delipidated using reverse phase high performance liquid chromatography protocol as described previously $[29,34]$ and employed in all ligand-binding experiments. For ANS, the excitation wavelength was $350 \mathrm{~nm}$ and fluorescence emission was collected in the range $420-600 \mathrm{~nm}$. Intrinsic fluorescence of protein was measured in presence and absence of oleic acid, excitation wavelength was set to $295 \mathrm{~nm}$ and emission was collected in the range $310-400 \mathrm{~nm}$. In all of the above case, the slit widths were set to $5 \mathrm{~nm}$ for both excitation and emission. All emission spectra were plotted and analysed using Microcal ORIGIN software.

\section{Protein mass spectrometry and N-teminal amino acid sequencing}

Mass spectrometric analyses and $\mathrm{N}$-terminal sequencing were carried out at the National Laboratory of Peptide and Protein Research (LANAIS PROEM, School of Pharmacy and Biochemistry, University of Buenos Aires) in a MALDI TOF TOF 4800 plus mass spectrometer (ABSciex, Framingham, MA). N-terminal sequencing was performed in a PPSQ-31A (Shimadzu Corporation, Japan). Direct $\mathrm{N}$-terminal sequencing by Edman degradation provided sequences for 18 and 19 amino-acids for P17 and P44, respectively. For P44, additional peptides were obtained following digestion with trypsin, Glu-C proteinase or Lys-C proteinase. Blastp searching of the nematode databases yielded no similar proteins for the P17 sequence. For P44, one pair of peptides overlapped, 
and another pair were also found to do so in preliminary searches. With these peptides edited together, there was a convincing fit with the amino acid sequence of a polycysteine and histidine-tailed protein isoform 2 from Trichinella spiralis (NCBI accession gb|AEQ29641).

\section{Results}

Somatic and pseudocoelomic fluid (PCF) proteins of adult D. renale

PCF and soluble proteins of body wall, intestine, testis, and ovary were separated by SDS PAGE (Fig. 1). The protein profile of PCF is dominated by two notably abundant proteins, one of $\mathrm{M}_{\mathrm{r}} 17,000$ (designated P17) and another of $\mathrm{M}_{\mathrm{r}}$ 44,000 (P44) in both males and females. The proteins of body wall, intestine, testis, and ovary showed little overlap with each other except for the common presence of a protein of similar $\mathrm{M}_{\mathrm{r}}$ to $\mathrm{P} 44$. The protein profile of $D$. renale PCF is different from those of the only other parasitic nematodes large and accessible enough for PCF to be recovered easily, namely the adults of large ascaridids such as Ascaris suum and Toxocara canis $[35,36]$. The most abundant proteins in adult ascaridid PCFs are approximately $14.4 \mathrm{kDa}$ monomers of the nematode polyprotein allergens (NPAs) [30, 37, 38], and a globin of approximately $43 \mathrm{kDa}[39,40]$. A recombinant form of the NPA from Ascaris suum, ABA-1A (syn. As-NPA-1A; [29]), was included here as a positive control, and there was no sign of an abundant protein of similar size in D. renale PCF (not shown).

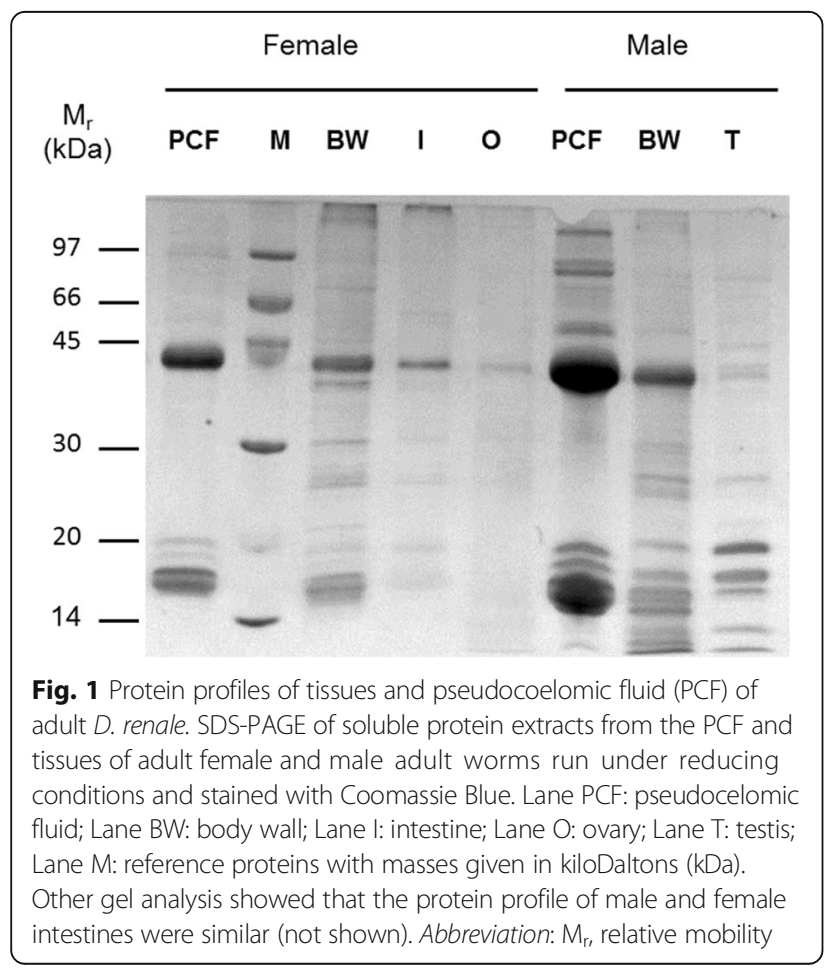

\section{Purification of $\mathrm{P} 17$ and $\mathrm{P} 44$ by gel filtration}

PCF was fractionated by size exclusion gel chromatography through a Superdex 75 column (Fig. 2a). The two major proteins were readily separable, as seen from the accompanying SDS-PAGE of the resulting fractions (Fig. $2 \mathrm{~b})$. The sizes of these proteins as calculated relative to the time of elution of standard calibration proteins approximated the values obtained from SDS-PAGE under reducing conditions (Fig. 1), indicating that both proteins eluted from the column as monomers, and may therefore exist as such in PCF. Protein mass spectrometry of the two provided molecular masses of 44,460 Da for P44 and 16,622 Da for P17 (data not shown). The P17 protein is intensely red, and retains its colour in gel filtration and in native non-reducing PAGE (see below), but not under SDS-PAGE. The red chromophore is probably, therefore, non-covalently attached, as is the haem prosthetic group in proteins such as vertebrate globins (haemoglobin, myoglobin, neuroglobin). P17's molecular mass is similar to that of the 'nemoglobins' that have been described from nematodes [41], but which are not related to vertebrate globins. The nematodes from which nemoglobins have been described are in clades (Clades II to V) that are phylogenetically remote from Clade I in which $D$. renale is now placed [42, 43], so P17's evolutionary relationship, if any, to nemoglobins remains to be established.

\section{Protein-associated lipids in $D$. renale PCF}

The most abundant proteins found in animal blood or haemolymph are often respiratory or lipid-carrier proteins. In order to determine the lipid classes present in PCF and associated with P17 or P44, Folch lipid extractions from PCF and the two purified proteins were carried out and analysed by TLC. As seen in Fig. 3, the lipids found in unfractionated PCF were heterogeneous and similar in type and relative concentrations to those of rat liver. In contrast, lipids found in association with P44 (and to a minor extent with P17) were fatty acids. As an additional screen, PCF was incubated with DAUDA [an 11-carbon fatty acid tagged at its omega (methyl) end with the environment-sensitive dansyl fluorophore; see Methods for details] prior to loading onto non-denaturing PAGE (Fig. 4). There would have been some loss of protein-bound DAUDA during electrophoresis because it should not have bound covalently, but a protein migrating to the same position as P44 was observed to bind the probe, as also did the ABA-1A positive control protein, but not P17 (compare Fig. 4a, b). Figure $4 \mathrm{c}$ shows a similar non-denaturing PAGE of PCF that had not been stained, as photographed under visible light. P17 retained its red colour under these conditions; a strong red band appeared at the $\mathrm{M}_{\mathrm{r}}$ for P17, 

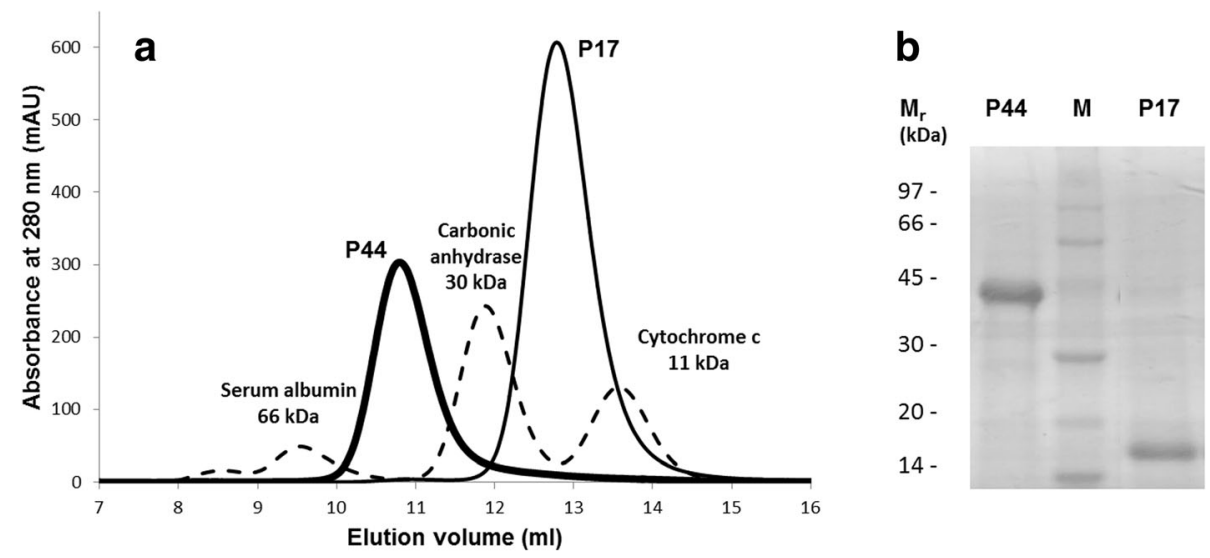

Fig. 2 Purification of the abundant P17 and P44 proteins of adult D. renale pseudocoelomic fluid. a Pure major gel filtration peaks of D. renale PCF correspond to the P17 and P44 proteins (solid lines), mass spectrometry of which yielded masses of 16,622 Da and 44,460 Da, respectively (see main text). Absorbance peaks from the three standard proteins are overlain (dashed lines). b SDS-PAGE analysis of the different fractions after gel filtration. Coomassie Blue-stained. Lane M: reference proteins with masses given in kiloDaltons (kDa). Abbreviation: $\mathrm{M}_{\mathrm{r}}$, relative mobility

but also two clear bands of lower $\mathrm{M}_{\mathrm{r}}$ that may indicate other isoforms or charge variants of the protein.

\section{Spectrofluorometric analysis of lipid-binding by P44}

The PCF of other large nematodes, such as adult ascaridids, have high concentrations of lipid-binding proteins, particularly the NPAs mentioned above. Given that fatty acids associated with P44 (Fig. 3), we further characterised the ligand-binding properties of the protein using environment-sensitive fluorescent probes and P44 from which any resident lipid had been removed by reversephase HPLC performed as previously described [34]. We

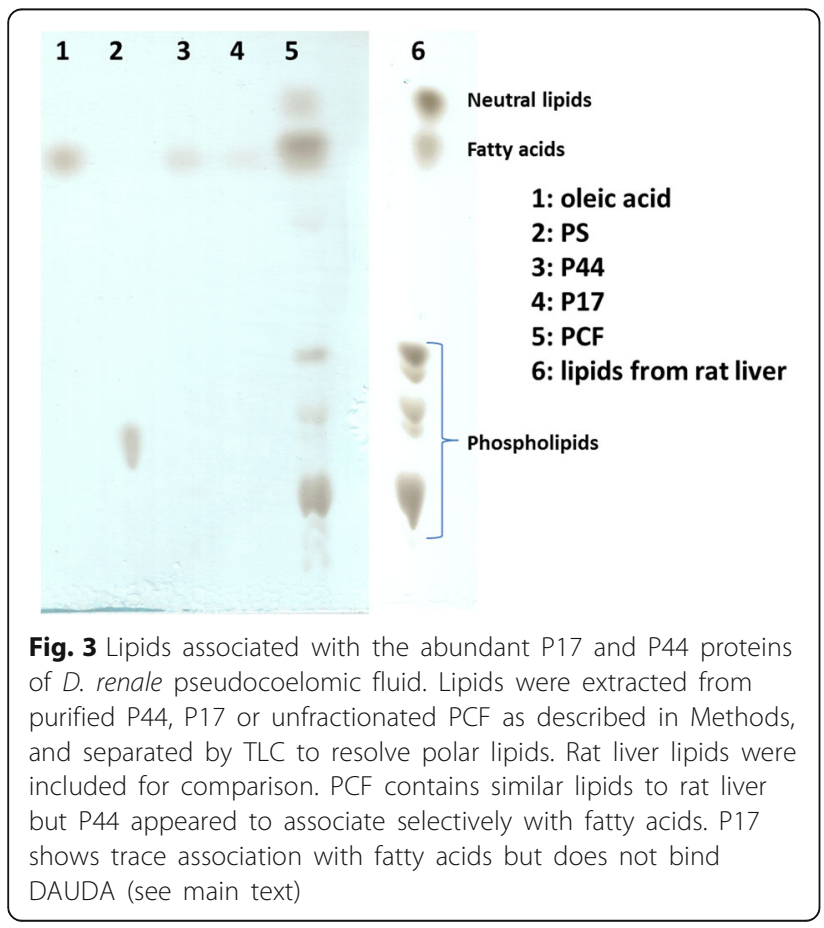

first used 8-anilinonaphthalene-1-sulfonic acid (ANS), a non-specific probe of hydrophobic sites in proteins, which exhibited a dramatic enhancement of fluorescence emission in the presence of P44 (Fig. 5a). Addition of oleic acid to preformed P44: ANS complexes resulted in displacement of ANS from the protein. We then used DAUDA, the environment-sensitive dansyl fluorophore that exhibits low florescence in water and that is markedly enhanced and blue-shifted in emission when in an apolar environment such as a protein binding site [44]. This probe binds to some but not all specialised fatty acid-binding proteins of mammals, and also to the NPAs and other lipid-binding proteins found only in nematodes (nematode fatty acid and retinol-binding proteins (FARs), and nemFABPs; [45-47]). DAUDA's fluorescence emission was dramatically enhanced when mixed with de-lipidated P44, and its peak wavelength of emission underwent a dramatic blue shift from $544 \mathrm{~nm}$ to $470 \mathrm{~nm}$ (Fig. 5b), which was similar to that seen with the wellcharacterised ABA-1 used as a control (not shown) [48]. Blue-shifts in DAUDA of this magnitude are rarely seen with, for instance, cytosolic fatty acid-binding proteins $[48,49]$ or vertebrate serum albumins [44], and is indicative of a highly apolar binding site environment. When oleic acid was added to preformed DAUDA:P44 complexes there was a clear displacement of the probe from the protein, which is indicative of the binding site being preferential for fatty acids and that the attached dansyl fluorophore is probably irrelevant to binding.

In some lipid-binding proteins the binding of a ligand alters the environment of a tryptophan (Trp) side chain that is detectable by a change in the intensity and/or wavelength of fluorescence emission by the Trp [50]. We do not yet know the complete amino-acid sequence of P44 but excitation of a sample of the de-lipidated 


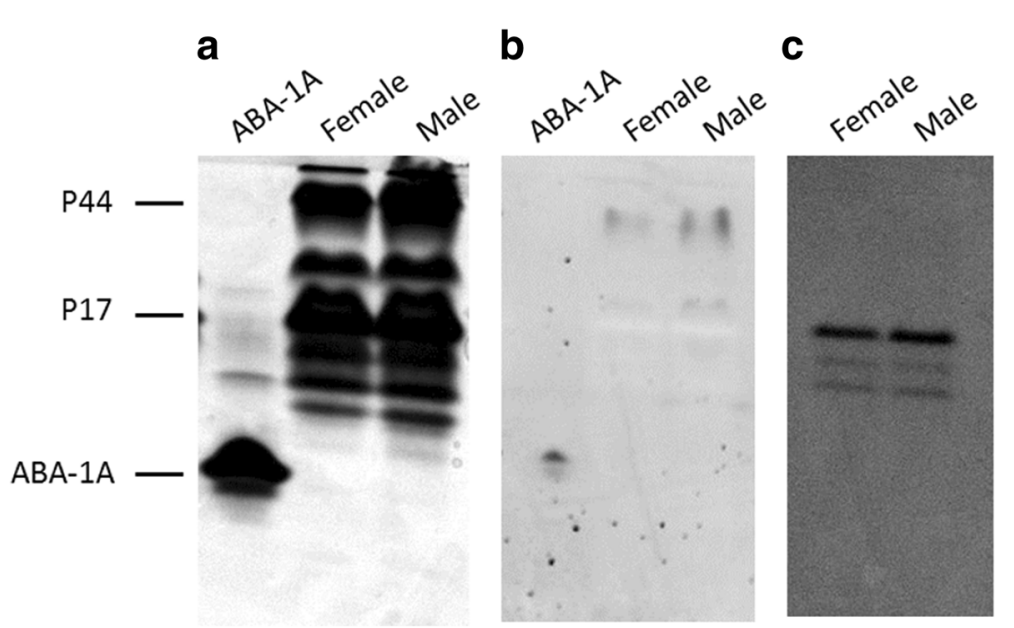

Fig. 4 Lipid-binding by proteins in D. renale pseudocoelomic fluid. a Native (non-SDS) polyacrylamide gel electrophoresis of adult worm PCF and the fatty acid-binding recombinant ABA-1A of Ascaris suum as a control. Coomassie Blue stained gel. $\mathbf{b}$ The same as (a) gel in which protein samples were pre-incubated with the environment-sensitive fluorescent fatty acid analogue DAUDA before electrophoresis, viewed under ultraviolet light, and the negative image of DAUDA's fluorescence emission is shown. Proteins migrating commensurate with P44 and ABA-1A in size associate with DAUDA indicative of lipid-binding activity. c Similar, unstained gel viewed under visible light is which only the intensely red P17 is visible. P17 loses its colour under SDS-PAGE (not shown), indicating that the red chromophore is not covalently bound. Comparison with (b) shows that P44, but not P17, binds DAUDA, which was also found to be the case in spectrofluorimetry (see main text)

protein at $295 \mathrm{~nm}$ (at which fluorescence emission by tryptophan dominates over that by phenylalanine and tyrosine) elicited an emission spectrum shown in Fig. 5c. With the Raman scatter of buffer subtracted, the peak wavelength of intrinsic florescence emission by $\mathrm{P} 44$ occurred at approximately $338 \mathrm{~nm}$. The fluorescence emission of Trps is sensitive to the polarity of the environment of its indole side chain such that full exposure to solvent water will yield an emission maximum at about $356 \mathrm{~nm}$, which is blue-shifted in proteins in which a Trp is buried $[28,29,51]$. In the case of P44, the wavelength of maximum emission is $338 \mathrm{~nm}$ (Fig. 5c), representing a blue shift of about $18 \mathrm{~nm}$ from that of a Trp that is fully exposed to solvent water (e.g. [28, 52]. We do not yet know the exact number of Trps in P44 so the emission could come from more than the four already found by $\mathrm{N}$-terminal sequencing (see below). The emission spectrum will therefore be a composite of emissions by two or more Trps that may have differing environments, but P44's intrinsic emission spectrum indicates the isolation of some at least of the protein's Trps from solvent water. If the environment of a Trp side chain is affected by protein binding to a lipid ligand then the emission spectrum may be further blue-shifted or increased in intensity [50]. With P44, however, the addition of oleic acid to de-lipidated protein did not cause a significant change in fluorescence emission intensity or peak wavelength, so it may be that none of the protein's Trps are close to or in the binding site, or affected by ligand-binding causing environmental change elsewhere in the molecule. Another possibility could be that a single Trp's environment is affected by lipidbinding to the protein, but that its altered emission spectrum is swamped by emission form other Trps that are not affected.

\section{Amino-acid sequence analysis}

From its size and ligand-binding characteristics, P44 appears to be a novel type of lipid-binding protein of nematodes. The blue shift in DAUDA emission upon binding is similarly extreme to that seen in the NPA and FAR proteins of nematodes [28, 47], but the posttranslationally processed forms of the former are approximately $14.4 \mathrm{kDa}$ (although some species have larger combined units [53] and the FAR proteins are all about $20 \mathrm{kDa}$ in size $[34,54,55]$. To investigate whether $\mathrm{P} 44$ exhibits any relationship to known proteins from nematodes, we obtained N-terminal and several internal peptide sequences (Fig. 6). Database searching revealed that the peptide sequences all align reasonably well with the sequence of a protein from Trichinella spiralis that is described as a poly-cysteine and histidine-tailed protein (PCHTP; Fig. 6) [56]. The similarities are collectively convincing given the alignments of cysteines and bulky hydrophobic amino acids such as tryptophan and phenylalanine. A similar degree of similarity was found with PCHTPs predicted for other species of Trichinella and also Trichuris trichiura, all of which are, like D. renale, Clade I nematodes. An N-terminal amino acid sequence was also obtained from P17 (TQNKPLLTAQMDXIHADA; single amino-acid code), but alignments even with putative globin-like proteins 


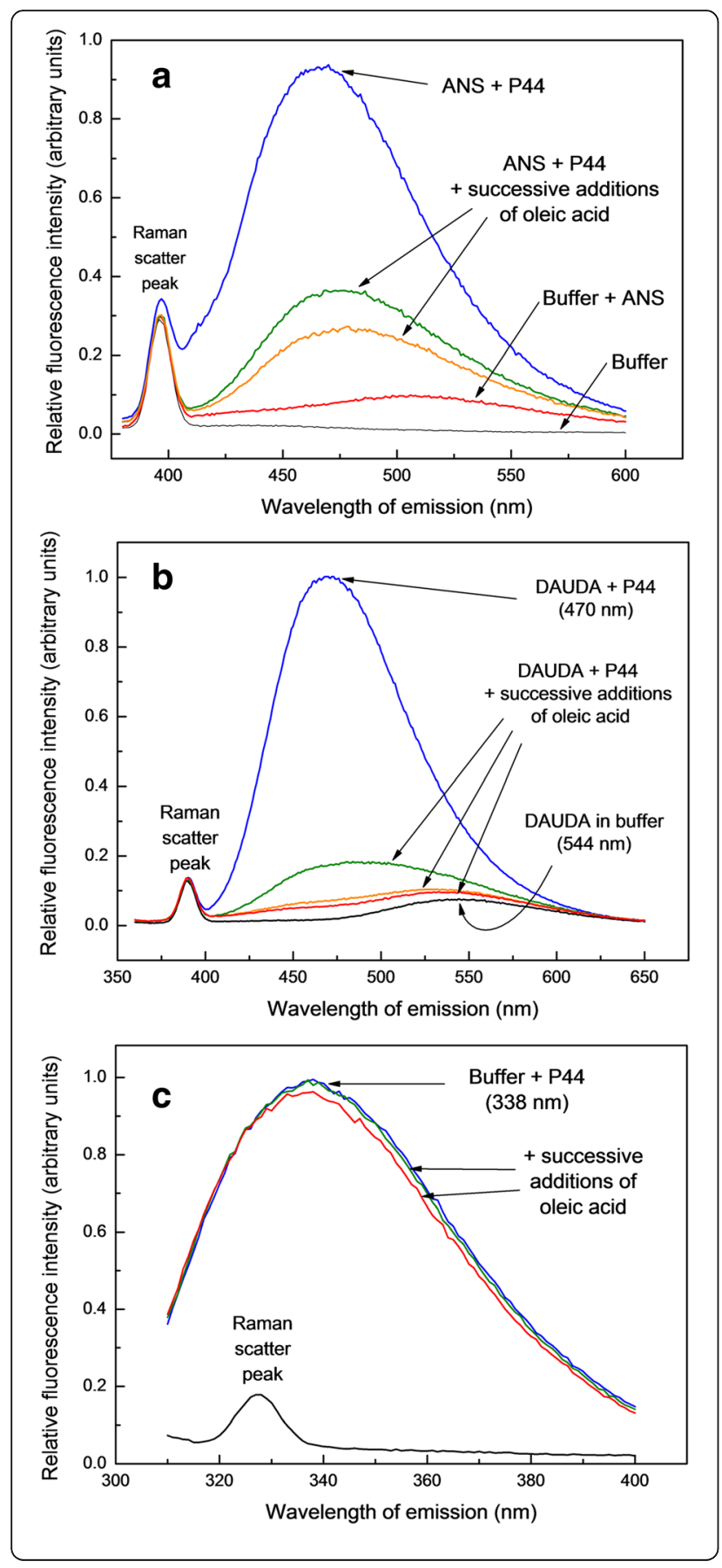

Fig. 5 Hydrophobic ligand-binding by D. renale P44. a Superdex 75purified and delipidated P44 (1.3 $\mu \mathrm{M})$ was added to the non-specific hydrophobic probe ANS $(3.3 \mu \mathrm{M})$ in PBS causing a dramatic increase in the probe's fluorescence emission. Successive additions of $0.5 \mu \mathrm{l}$ of $1 \mathrm{mM}$ oleic acid partially reversed the fluorescence enhancement. Excitation wavelength $=350 \mathrm{~nm}$. b P44 $(1.3 \mu \mathrm{M})$ added to the dansyl fluorophore-tagged fatty acid DAUDA $(0.3 \mu \mathrm{M})$ in buffer yielding a dramatic increase in fluorescence intensity and blue shift in DAUDA's peak wavelength of emission from $544 \mathrm{~nm}$ to $470 \mathrm{~nm}$. This was reversed with successive additions of $0.5 \mu$ of $1 \mathrm{mM}$ oleic acid solution. Similar experiments using D. renale P17 revealed no binding of DAUDA (not shown). Excitation wavelength $=345 \mathrm{~nm}$. c Intrinsic (predominantly tryptophan) protein fluorescence emission by P44. P44 in buffer was excited at $295 \mathrm{~nm}$ producing peak fluorescence emission at $338 \mathrm{~nm}$. Successive additions of $0.5 \mu \mathrm{l}$ of $1 \mathrm{mM}$ oleic acid solution in ethanol to $300 \mu$ protein in PBS produced only very slight if any changes in emission intensity and wavelength of peak emission. The spectrum of buffer alone (shown) was subtracted from each of the P44 intrinsic fluorescence emission spectra

from Clade I nematodes (Trichinella and Trichuris species) in current databases were not convincing.

\section{Discussion}

We present a protein biochemical analysis of the giant kidney nematode $D$. renale. Species of animal-parasitic nematode are scattered across the Phylum Nematoda, but those in Clade I, to which D. renale belongs [43]. The Dorylaimia, have received little attention except for those in the genera Trichinella and Trichuris, representatives of which are the subjects of intense immunological and molecular biological research. We have begun work on $D$. renale because of its veterinary and potential human medical importance, but also because of its phylogenetic position within a relatively understudied clade of nematodes. The sheer size of the adult worms presents a significant advantage for investigating their molecular and cellular components, equalled elsewhere only by the ascaridids of Clade III. This allowed us to isolate different tissues from both males and females, and their PCF can be readily extracted to provide plentiful quantities of its constituent proteins. In that PCF we found two proteins that were particularly abundant, one that confers the intense red colour of the adult parasites and may be haem-containing, and the other a potentially novel type of lipid-binding protein.

The protein profile of the PCF of adult $D$. renale (Clade I) males and females is completely different from that of the equivalently-sized Ascaris and Toxocara spp. of clade III [35]. The last common ancestor of the two clades is thought to have lived between 500 and 650 million years ago [57]. The major proteins in PCF of these large gut-dwelling ascaridids are the lipid-binding NPAs (e.g. aba-1 of Ascaris) [28, 38], but we found no indication that they are present in $D$. renale. This was somewhat unexpected given that this family of proteins has 


\begin{tabular}{|c|c|c|}
\hline P44 peptide & Amino acid sequence & As edited or combined for alignment \\
\hline D.renale_1 & DQPDCPAFGEWKPWTDQCL & DQPDCPAFGEWKPWTDQCL \\
\hline D.renale_2 & TEWSQCLXF & \\
\hline D.renale_3 & WSQCLWFPLSXMAT ] & TEWSQCLWFPLSXMAT \\
\hline D.renale_4 & CGFCSFSVR & CGFCSFSVR \\
\hline D.renale_5 & DVCTLTPHPK & \\
\hline D.renale_6 & XSCGKDEHCETCGDV & SCGKDEHCEICGDVCTLIPHPK \\
\hline D.renale_7 & DYADILWYLPXA & DYADILWYLPXA \\
\hline
\end{tabular}
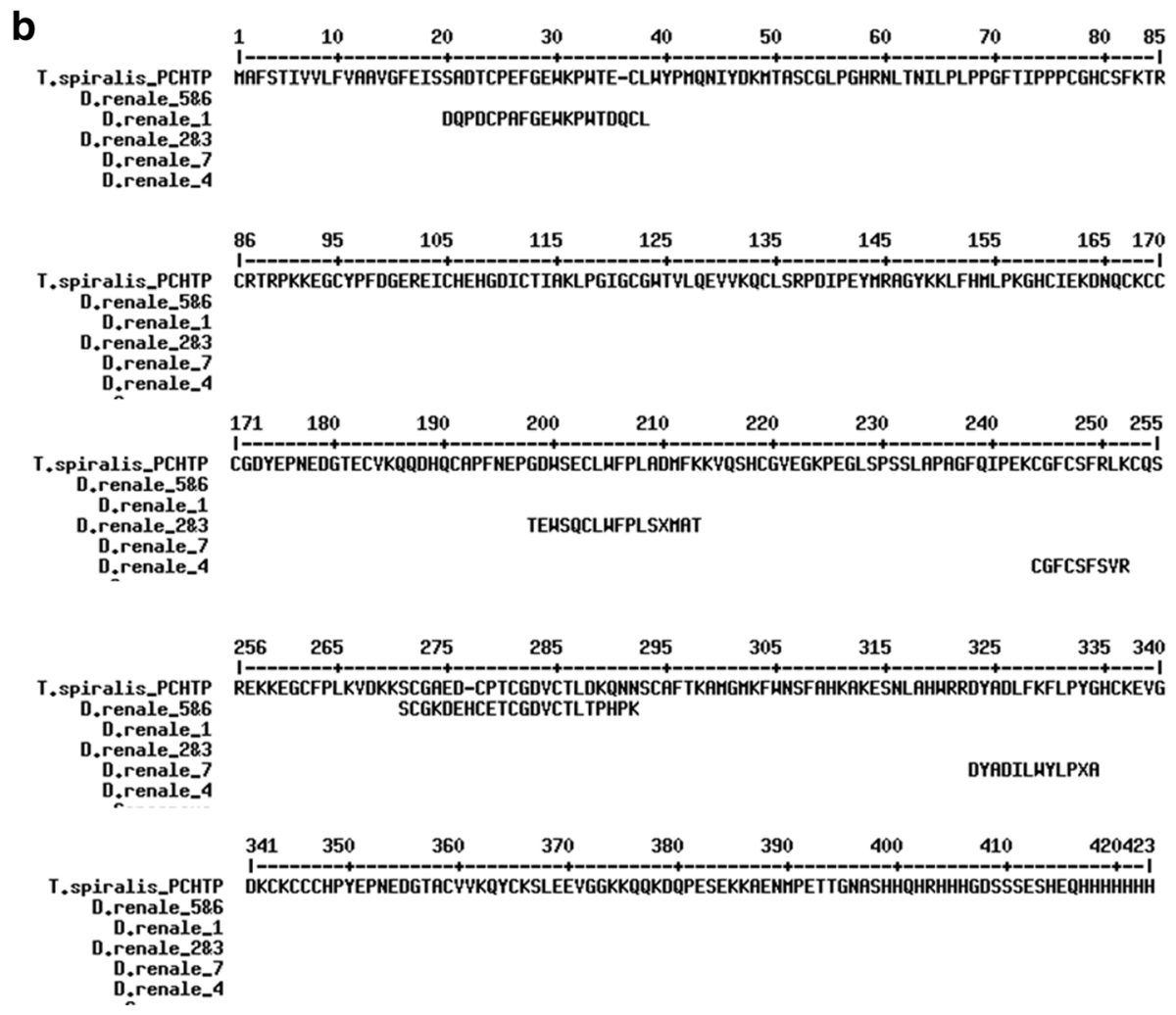

Fig. 6 Putative orthologues of D. renale P44. a Peptide sequences from P44 and how they were combined or edited for the alignment. Sequences are given using the single letter code for amino-acids. $\mathbf{b}$ Alignment between the peptides obtained from P44 and the full predicted amino-acid sequence of the poly-cysteine and histidine-tailed protein isoform 2 from Trichinella spiralis (Ts-PCHTP; NCBI accession AEQ29641). The alignment was made using MultAlin set for the default blosum62 substitution matrix (http://multalin.toulouse.inra.fr/multalin/multalin.html). Though not shown, the alignment was similarly good with sequences from other species of Trichinella, and with a PCHTP sequence from Trichuris trichiura (NCBI accession CDW54015). The first 21 amino-acids in the T. spiralis sequence are predicted to be a cleavable signal peptide by SignalP (www.cbs.dtu.dk/services/SignalP/), the predicted mature protein therefore beginning close to where the D. renale P44 N-terminal peptide sequence begins (D.renale_1)

been found in species of nematode of clades III, IV and $\mathrm{V}$ [58]. Also, to date, we have found no evidence yet of NPA-encoding genes in the genome databases for Trichinella spiralis or Trichuris spp. It is therefore possible that the NPAs either appeared as novelties in the common progenitor of the Rhabditida (Clades III, IV and V; little is known of the biochemistry of Clade II nematodes), or that they were lost in Clade I.

Nematodes produce and secrete an unexpectedly wide range of unusual lipid-binding protein types, many of which are structurally distinct from those of their hosts, and which have been recognised as major antigens in infection $[59,60]$. The acquisition and transport of lipids is crucial to these organisms because of their inability to synthesise complex lipids [61,62], and, in the case of large parasites, they need to distribute insoluble lipids between the site of absorption to the tissues where they are consumed. Hypothetical roles for helminth lipidbinding proteins include internal functions common to most multicellular organisms, such as distribution of 
energy stores and for cell-cell signalling in development. The secretion of lipid-binding proteins by parasites may be additionally involved in interference with, and manipulation of, a host's lipid-based cellular or immune functions [63, 64].

The NPAs and FAR proteins of nematodes have no recognizable structural counterparts in other animal groups $[59,60]$. While there is much yet to establish, it is possible that P44 represents another novel class of lipid-binding protein that may be specific to nematodes. The protein with which we found amino-acid sequence similarities to $\mathrm{P} 44$ is an unusual poly-cysteine and histidine-tailed protein (PCHTP) from species of the genera Trichinella (and Trichuris; Fig. 6). Radoslavov et al. [56] stated that they found the T. spirals protein Ts-PCHTP to interact with DAUDA but not convincingly so. That could be due to a misfolding of the recombinant form of the protein that was used given its unusually high number of cysteines, potentially leading to a high proportion of incorrectly disulphide-bonded protein. Also, it might be necessary to delipidate the protein for DAUDA binding to be discernible. Interestingly, these PCHTPs are unusually rich in histidines, which is also true of some units of the NPAs, in which the histidine-rich peptides have been found to bind zinc ions (M.W. Kennedy and A. Cooper, unpublished). For the moment, though, P44 now joins the select group of proteins, all specific to nematodes, that induce the greatest blue shift in peak fluorescence emission of the environmental-sensitive probe DAUDA, which is greater than that observed with specialist lipid-binding proteins of vertebrates such as cytoplasmic fatty acid binding proteins and serum albumins $[44,46,48]$.

NPAs appear to be the major lipid carriers in the PCF of large adult ascaridids (Ascaris spp. and Toxocara canis), and have been reported in many species in Clades III, IV and V $[28,48]$. NPAs are synthesized as large tandem arrays of units that have similar amino-acid sequences and lipid-binding properties that are posttranslationally cleaved down to multiple copies of about $14.4 \mathrm{kDa}$ units $[28,48,65]$. In vertebrates, the counterpart lipid carriers in blood would be the serum albumins, which are about $67 \mathrm{kDa}$, monomeric, carry fatty acids and a range of other apolar and polar ligands, and perform an important osmotic function in blood. Serum albumin itself is derived from gene duplication events [66] to create a protein of a size that will not be lost through the excretory system's size filter of vertebrate kidneys. A surprise, therefore, is that the single, small, highly abundant units of the NPAs are not lost from a nematode's PCF unless there is a low molecular size filter in their excretory systems, or a recovery system to avoid loss. This problem may also apply to P17 of $D$. renale, but possibly not to its $\mathrm{P} 44$ because of its larger size. While we find strong evidence that P44 is an unusual type of lipid carrier protein, it remains to be established whether it also has other transporter functions.

The P17 protein of $D$. renale is intensely red, abundant in PCF, and must account for the dramatic red colour of the worms. It is probably haem-containing, in common with many respiratory proteins in animals, and the red colour is indicative of it having iron at its core [67]. P17 may therefore be a member of a class of nematodespecific proteins termed "nemoglobins" to distinguish them from the unrelated haemoglobins of vertebrates (although the term "haemoglobin" still persists for these proteins in the nematode literature [41]). The precise function of nemoglobins is still debated but they are likely to be oxygen transporter proteins similar to the haemoglobins and myoglobins of vertebrates, although they may also serve to sequester oxygen in species that are micro- or anaerobic [41, 68]. We obtained Nterminal amino acid sequence from P17, but we have not yet found any similar proteins in the nematode databases.

As noted above, proteins from the "oesophagus" of adult $D$. renale provide improved target antigens for serological detection of dogs infected or exposed to this parasite, including those that are not releasing parasite eggs through their urine [25]. It will be interesting to establish whether the parasite's PCF is of equivalent value, especially given the relative ease with which it can be obtained in quantity from adult parasites. We do not as yet know whether the tissue-migratory pre-adult stages of $D$. renale produce all or any of the PCF proteins we observed in adults, and understanding the developmental protein expression pattern of the parasite would clearly be valuable in designing an effective immunoassay for detecting pre-adult, single sex, and ectopic infections.

In general terms this work is aimed at discovering species-specific proteins from $D$. renale that may be useful as new diagnostic markers for use in dogs and humans, and also potential new immune- or chemotherapeutic targets. The development of diagnostic methods of enhanced specificity and sensitivity will also contribute to improved understanding of the epidemiology of $D$. renale. Additionally, our results may not only bring to light LBPs from parasitic helminths that may be structurally novel, but could also reveal new aspects of lipid metabolism of parasitic nematodes, a barely explored area in Clade I nematodes. The functional data that may emerge from this work could also contribute to a better understanding of the host-parasite relationship in this unusual infection. Analysis of P44 in particular has also emphasised the closeness of $D$. renale to other highly pathogenic parasitic members of Clade I 
nematodes, and may provide valuable insights to the lipid handling systems of parasites such as Trichinella and Trichuris species.

\section{Conclusions}

In this work our findings begin to illuminate the biology of this unusual parasite at the molecular level. We have described two major proteins in the PCF: P44, which was revealed to exhibit lipid-binding activity, and P17, a possible "nemoglobin". These findings are also of importance given that they provide material and information pertinent to the function of the components of smaller related species.

\section{Acknowledgements}

We are greatly indebted to the staff at National Laboratory of Peptide and Protein Research (LANAIS PROEM, School of Pharmacy and Biochemistry, University of Buenos Aires) for all their help in mass spectrometry and peptide sequencing, specifically Carlos Pavan and Norma Sterin Speziale.

\section{Funding}

This work was supported by the National Research Council of Argentina (CONICET, PIP 0739 - GRF) and the National University of La Plata (M188 - BC), and also the Wellcome Trust (UK) under grant number 083625 (to MWK and $\mathrm{BC}$ ). The funders had no role in study design, data collection and analysis, decision to publish, or preparation of the manuscript.

\section{Availability of data and materials}

All data generated or analysed during this study are included in this published article.

\section{Authors' contributions}

ANG, MWK and GRF conceived and designed the experiments. MJB and NER participated in obtaining biological samples. ANG, MJB and GRF performed the experiments. ANG, MWK, BC and GRF analysed the data. ANG, MWK, BC and GRF wrote the paper in consultation with all authors. All authors read and approved the final manuscript.

\section{Ethics approval}

All parasite material was obtained during veterinary treatment of $D$. renaleinfected dogs in surrounding areas of La Plata, Argentina. Dogs that were found to be positive for dioctophymosis by urine sedimentation and ultrasonography were treated by nephrectomy of the (non-functional) infected kidney carried out by veterinary surgeons using standard anaesthetic, surgical, and recovery procedures appropriate for the condition, and with prior informed and signed consent of the owners.

\section{Consent for publication}

Not applicable.

\section{Competing interests}

The authors declare that they have no competing interests.

\section{Publisher's Note}

Springer Nature remains neutral with regard to jurisdictional claims in published maps and institutional affiliations.

\section{Author details}

'Instituto de Investigaciones Bioquímicas de La Plata (INIBIOLP), Facultad de Ciencias Médicas, Universidad Nacional de La Plata, La Plata, Argentina. ${ }^{2}$ Institute of Biodiversity, Animal Health and Comparative Medicine, University of Glasgow, G12 8QQ, Glasgow, UK. ${ }^{3}$ School of Life Sciences, University of Glasgow, G12 8QQ, Glasgow, UK. ${ }^{4}$ Laboratorio de Parasitosis Humanas y Zoonosis Parasitarias, Cátedra de Parasitología Comparada, Facultad de Ciencias Veterinarias, Universidad Nacional de La Plata, La Plata, Argentina.
Received: 19 June 2017 Accepted: 17 September 2017

Published online: 27 September 2017

\section{References}

1. Nakagawa TLDR, Bracarense APFRL, dos ACF R, Yamamura MH, Headley SA. Giant kidney worm (Dioctophyme renale) infections in dogs from northern Paraná. Brazil Vet Parasitol. 2007:145:366-70.

2. Ferreira $\mathrm{VL}$, Medeiros FP, July JR, Raso TF. Dioctophyme renale in a dog: clinical diagnosis and surgical treatment. Vet Parasitol. 2010;168:151-5.

3. Pereira BJ, Girardelli GL, Trivilin LO, Lima VR, de Nunes L, C, IVF M. The occurrence of dioctophymosis in dogs from Municipality of Cachoeiro do Itapemirim in the State of Espírito Santo, Brazil, from May to December of 2004. Rev Bras Parasitol Vet. 15:123-5.

4. Mesquita LR, Rahal SC, Faria LG, Takahira RK, Rocha NS, Mamprim MJ, et al. Pre- and post-operative evaluations of eight dogs following right nephrectomy due to Dioctophyme renale. Vet Q. 2014;34:167-71.

5. Kommers DG. da Silva Ilha RM, Lombardo de Barros SC. Dioctophymosis in dogs: 16 cases. Ciência Rural. 1999;29:517-22.

6. Rocha UF, Serra RGGR. Parasitism by Dioctophyme renale (Goeze, 1782) in sloth (Choloepus didactylus) (Linnaeus, 1758). Rev Fac Farm Bioq São Paulo. 1965;3:325-34.

7. Ribeiro CT, Verocai GG, Tavares LER. Dioctophyme renale (Nematoda, Dioctophymatidae) infection in the crab-eating fox (Cerdocyon thous) from Brazil. J Wildl Dis. 2009:45:248-50.

8. Duarte J, Costa AMB, Katagir S, Martins JA, Oliveira ME, Ribeiro CM. Parasitism by Dioctophyme renale (Goeze, 1782) in maned wolf (Chrysocyon brachyurus). Brazil Veterinária e Zootec. 2013;20:52-6.

9. Squilasse AF, Monteiro ANB, Martins MX, Thomé HE. Dioctophyme renale in guará wolf (Chrysocyon brachyurus) - "post mortem" case report. Ciência Anim. 2015;8:566-73.

10. Mattos Varzone JR, Cury Thomaz de Aquino LP, Rodovalho MV de T. Macroscopic findings of lesions resulting from parasitism by Dioctophyme renale in Lobo-Guará (Chrysocyon brachyurus) - case report. Ensaios e Ciência Ciências Biológicas, Agrárias e da Saúde. 2008;XIl:171-8.

11. Maia OB, Gouveia AMG. Birth and mortality of maned wolves Chrysocyon brachyurus (Illiger, 1811) in captivity. Braz J Biol. 2002;62:25-32.

12. Deem SL, Emmons LH. Exposure of free-ranging maned wolves (Chrysocyon brachyurus) to infectious and parasitic disease agents in the Noël Kempff Mercado National Park. Bolivia J Zoo Wildl Med. 2005;36:192-7.

13. Myers N, Mittermeier RA, Mittermeier CG, da Fonseca GA, Kent J. Biodiversity hotspots for conservation priorities. Nature. 2000;403:853-8.

14. Beaver PC, Theis JH. Diocytophymatid larval nematode in a subcutaneous nodule from man in California. Am J Trop Med Hyg. 1979;28:206-12.

15. Urquhart GM, Armour J, Duncan JL, Jennings W, Dunn AM. Veterinary parasitology. 2nd ed. Harlow: Longman; 1996.

16. Verocai GG, Measures LN, Azevedo FD, Correia TR, Fernandes JI, Scott FB. Dioctophyme renale (Goeze, 1782) in the abdominal cavity of a domestic cat from Brazil. Vet Parasitol. 2009;161:342-4.

17. Li G, Liu C, Li F, Zhou M, Liu X, Niu Y. Fatal bilateral dioctophymatosis. J Parasitol. 2010;96:1152-4.

18. Katafigiotis I, Fragkiadis E, Pournaras C, Nonni A, Stravodimos KG. A rare case of a 39 year old male with a parasite called Dioctophyme renale mimicking renal cancer at the computed tomography of the right kidney. A case report. Parasitol Int. 2013;62:459-60.

19. Venkatrajaiah N, Kalbande SH, Rao GVN, Reddy VC, Reddy SH, Rao PR, et al. Dioctophymatosis renalis in humans: first case report from India. J Assoc Physicians India. 2014;62:70-3.

20. Kuehn J, Lombardo L, Janda WM, Hollowell CMP. Giant kidney worms in a patient with renal cell carcinoma. BMJ Case Rep. 2016:2016:bcr2015212118.

21. Pedrassani D, Lux Hoppe EG, Avancini N, do Nascimento AA. Morphology of eggs of Dioctophyme renale Goeze, 1782 (Nematoda: Dioctophymatidae) and influences of temperature on development of first-stage larvae in the eggs. Rev Bras Parasitol Vet. 1782;18:15-9.

22. Mascarenhas CS, Müller G. Third-stage larvae of the enoplid nematode Dioctophyme renale (Goeze, 1782) in the freshwater turtle Trachemys dorbigni from southern Brazil. J Helminthol. 2015;89:630-5.

23. Georgi JR, Georgi ME. Canine clinical parasitology. 1st ed. Malvern: Lea \& Febiger; 1991

24. Lima VF, Ramos RA, Lepold R, Cringoli G, Rinaldi L, Faustino MA, et al. Use of the FLOTAC technique to diagnosing parasites of the urinary tract of dogs. Parasitol Res. 2016;115:1737-9. 
25. Pedrassani D, do Nascimento AA, André MR, Machado RZ. Improvement of an enzyme immunosorbent assay for detecting antibodies against Dioctophyme renale. Vet Parasitol. 2015;212:435-8.

26. Bradford MM. A rapid and sensitive method for the quantitation of microgram quantities of protein utilizing the principle of protein-dye binding. Anal Biochem. 1976;72:248-54.

27. Uversky VN. Use of fast protein size-exclusion liquid chromatography to study the unfolding of proteins which denature through the molten globule. Biochemistry. 1993;32:13288-98.

28. Kennedy MW, Brass A, McCruden AB, Price NC, Kelly SM, Cooper A. The ABA-1 allergen of the parasitic nematode Ascaris suum: fatty acid and retinoid binding function and structural characterization. Biochemistry. 1995; 34:6700-10.

29. Meenan N a G, Ball G, Bromek K, Uhrín D, Cooper A, Kennedy MW, et al. Solution structure of a repeated unit of the ABA-1 nematode polyprotein allergen of Ascaris reveals a novel fold and two discrete lipid-binding sites. PLoS Negl Trop Dis. 2011;5:-e1040.

30. Xia Y, Spence HJ, Moore J, Heaney N, McDermott L, Cooper A, et al. The ABA-1 allergen of Ascaris lumbricoides: sequence polymorphism, stage and tissue-specific expression, lipid-binding function, and protein biophysical properties. Parasitology. 2000;120:211-24.

31. Folch J, Lees M, Sloane Stanley GH. A simple method for the isolation and purification of total lipides from animal tissues. J Biol Chem. 1957;226:497-509.

32. Obal G, Ramos AL, Silva V, Lima A, Batthyany C, Bessio Ml, et al. Characterisation of the native lipid moiety of Echinococcus granulosus antigen B. PLoS Negl Trop Dis. 2012;6:e1642.

33. Wilkinson $\mathrm{TCl}$, Wilton DC. Studies on fatty acid-binding proteins. The detection and quantification of the protein from rat liver by using a fluorescent fatty acid analogue. Biochem J. 1986;238

34. Rey-Burusco MF, Ibanez-Shimabukuro M, Gabrielsen M, Franchini GR, Roe AJ, Griffiths K, et al. Diversity in the structures and ligand-binding sites of nematode fatty acid and retinol-binding proteins revealed by Na-FAR-1 from Necator americanus. Biochem J. 2015;471:403-14.

35. Kennedy MW, Qureshi F, Fraser EM, Haswell-Elkins MR, Elkins DB, Smith HV. Antigenic relationships between the surface-exposed, secreted and somatic materials of the nematode parasites Ascaris lumbricoides, Ascaris suum, and Toxocara canis. Clin Exp Immunol. 1989;75:493-500.

36. Kennedy MW, Qureshi F, Haswell-Elkins M, Elkins DB. Homology and heterology between the secreted antigens of the parasitic larval stages of Ascaris lumbricoides and Ascaris suum. Clin Exp Immunol. 1987;67:20-30.

37. Kennedy MW. The nematode polyprotein allergens/antigens. Parasitol Today. 2000;16:373-80.

38. Kennedy MW, Qureshi F. Stage-specific secreted antigens of the parasitic larval stages of the nematode Ascaris. Immunology. 1986;58:515-22.

39. Davenport HE. The haemoglobins of Ascaris lumbricoides. Proc R Soc London Ser B, Biol Sci. 1949;136:255-70.

40. Goldberg DE. The enigmatic oxygen-avid hemoglobin of Ascaris. BioEssays. 1995;17:177-82

41. Blaxter ML. Nemoglobins: Divergent nematode globins. Parasitol Today. 1993;9:353-60

42. Blaxter M, Koutsovoulos $\mathrm{G}$. The evolution of parasitism in Nematoda. Parasitology. 2015;142:S26-39.

43. Koehler AV, Hoberg EP, Torres-Pérez F, Cook JA. A molecular view of the superfamily Dioctophymatoidea (Nematoda). Comp Parasitol. 2009;76:100-4.

44. Wilton DC. The fatty acid analogue 11-(dansylamino)undecanoic acid is a fluorescent probe for the bilirubin-binding sites of albumin and not for the high-affinity fatty acid-binding sites. Biochem J. 1990;270:163-6.

45. Moore J, Mcdermott L, Price NC, Kelly SM, Cooper A, Kennedy MW. Sequence-divergent units of the ABA-1 polyprotein array of the nematode Ascaris suum have similar fatty-acid- and retinol-binding properties but different binding-site environments. Biochem J. 1999;343:337-43

46. McDermott L, Moore J, Brass A, Price NC, Kelly SM, Cooper A, et al. Mutagenic and chemical modification of the ABA-1 allergen of the nematode Ascaris: consequences for structure and lipid-binding properties. Biochemistry. 2001;40:9918-26.

47. Kennedy MW, Garside LH, Goodrick LE, McDermott L, Brass A, Price NC, et al. The Ov20 protein of the parasitic nematode Onchocerca volvulus. A structurally novel class of small helix-rich retinol-binding proteins. J Biol Chem. 1997;272:29442-8.

48. Kennedy MW. The polyprotein lipid-binding proteins of nematodes. Biochim Biophys Acta. 2000;1476:149-64.
49. Veerkamp JH, van Moerkerk HT, Prinsen CF, van Kuppevelt TH. Structural and functional studies on different human FABP types. Mol Cell Biochem. 1999;192:137-42.

50. De Gerónimo E, Hagan RM, Wilton DC, Córsico B. Natural ligand binding and transfer from liver fatty acid binding protein (LFABP) to membranes. Biochim Biophys Acta. 2010;1801:1082-9.

51. Eftink MR, Ghiron CA. Exposure of tryptophanyl residues in proteins. Quantitative determination by fluorescence quenching studies. Biochemistry. 1976;15:672-80.

52. Kennedy MW, Scott JC, Lo S, Beauchamp J, McManus DP. Sj-FABPC fattyacid-binding protein of the human blood fluke Schistosoma japonicum: structural and functional characterization and unusual solvent exposure of a portal-proximal tryptophan residue. Biochem J. 2000;349(Pt 1):377-84.

53. Britton C, Moore J, Gilleard JS, Kennedy MW. Extensive diversity in repeat unit sequences of the cDNA encoding the polyprotein antigen/allergen from the bovine lungworm Dictyocaulus viviparus. Mol Biochem Parasitol. 1995;72:77-88.

54. Solovyova AS, Meenan N, McDermott L, Garofalo A, Bradley JE, Kennedy MW, et al. The polyprotein and FAR lipid-binding proteins of nematodes: shape and monomer/dimer states in ligand-free and bound forms. Eur Biophys J. 2003;32:465-76.

55. Prior A, Jones JT, Blok VC, Beauchamp J, McDermott L, Cooper A, et al. A surface-associated retinol- and fatty acid-binding protein (Gp-FAR-1) from the potato cyst nematode Globodera pallida: lipid-binding activities, structural analysis and expression pattern. Biochem J. 2001;356(Pt 2):387-94.

56. Radoslavov G, Jordanova R, Teofanova D, Georgieva K, Hristov P, SalomoneStagni $M$, et al. A novel secretory poly-cysteine and histidine-tailed metalloprotein (Ts-PCHTP) from Trichinella spiralis (Nematoda). PLoS One. 2010;5

57. Mitreva M, Blaxter ML, Bird DM, McCarter JP. Comparative genomics of nematodes. Trends Genet. 2005;21:573-81.

58. Kennedy MW. The polyprotein allergens of nematodes (NPAs) - structure at last, but still mysterious. Exp Parasitol. 2011;129:81-4.

59. Franchini GR, Pórfido JL, Ibáñez Shimabukuro M, Rey Burusco MF, Bélgamo JA, Smith BO, et al. The unusual lipid-binding proteins of parasitic helminths and their potential roles in parasitism and as therapeutic targets. Prostaglandins Leukot Essent Fat Acids. 2015;93:31-6.

60. Kennedy MW, Córsico B, Cooper A, Smith BO. The unusual lipid-binding proteins of nematodes: NPAs, nemFABPs and FARs. In: Kennedy MW, Harnett W, editors. Parasitic nematodes: molecular biology, biochemistry and immunology. Wallingford: CABI. p. 397-412.

61. Barrett J. Nutrition and biosynthesis. In: Biochemstry of Parasitic helminths. MacMillan Publishers Ltd.; 1981. p. 149-244.

62. Barrett J. Developmental aspects of metabolism in parasites. Int J Parasitol. 1987;17:105-10.

63. Cheng X, Xiang Y, Xie H, Xu C-L, Xie T-F, Zhang C, et al. Molecular characterization and functions of fatty acid- and retinoid-binding protein gene (Ab-far-1) in Aphelenchoides besseyi. PLoS One. 2013;8:e66011.

64. Iberkleid I, Sela N, Brown MS. Meloidogyne javanica fatty acid-and retinolbinding protein (Mj-FAR-1) regulates expression of lipid-, cell wall-, stressand phenylpropanoid-related genes during nematode infection of tomato. BMC Genomics. 2015;16

65. Tweedie S, Paxton WA, Ingram L, Maizels RM, McReynolds LA, Selkirk ME. Brugia pahangi and Brugia malayi: a surface-associated glycoprotein (gp15/ 400 ) is composed of multiple tandemly repeated units and processed from a 400-kDa precursor. Exp Parasitol. 1993;76:156-64.

66. He XM, Carter DC. Atomic structure and chemistry of human serum albumin. Nature. 1992;358:209-15.

67. Wilson MT, Reeder BJ. Oxygen-binding haem proteins. Exp Physiol. 2008;93: 128-32.

68. Adducco V. The red substance of Eustrongylus gigas. Arch Ital Biol. 1889;11: 52-69. 